\title{
МЕСТО И РОЛЬ ЗАМЕСТИТЕЛЯ ДИРЕКТОРА ПО НАУЧНО-МЕТОДИЧЕСКОЙ РАБОТЕ В ШКОЛЕ
}

\author{
Стерхов $A . A$.
}

\author{
Гимназия во имя Святителя Николая Чудотворца, \\ г. Сургут, Российская Федерация
}

Статья посвящена исследованию места и роли заместителя директора по научно-методической работе в современной российской школе. Выявлены личностные и профессиональные качества, необходимые для эффективной работы в указанной должности. Рассмотрены основные аспекты деятельности заместителя директора по научно-методической работе в рамках эффективного менеджмента, направленного на модернизачию и развитие общеобразовательной организации. Сделан вывод о необходимости превращения школь в изентр подготовки к полноиченной социализации личности обучающегося в современном государстве и обществе.

Ключевые слова: заместитель директора; менеджмент; методическое сопровождение; научно-методическая работа; педагог.

\section{THE PLACE AND ROLE OF THE DEPUTY DIRECTOR ON SCIENTIFICALLY-METHODICAL WORK AT SCHOOL}

\author{
Sterkhov A.A. \\ Grammar school in the name of St. Nicholas, \\ Surgut, Russian Federation
}

The article is devoted to the study of the place and role of the Deputy Director for scientific and methodological work in the modern Russian school. Personal and professional qualities necessary for effective work in the specified position are revealed. The main aspects of activity of the 
Deputy Director on scientific and methodical work within the effective management directed on modernization and development of the educational organization are considered. The conclusion is made about the need to turn the school into a training center for the full socialization of the student in the modern state and society.

Keyword: Deputy Director; management; methodological support; scientific and methodical work; teacher.

\section{Введение}

В системе общего образования современной России много внимания уделяется работе заместителей директора по учебно-воспитательной и воспитательной работе, и крайне мало освещается значение и роль заместителя директора по научно-методической работе в функционировании общеобразовательной организации как целостного и бесперебойно работающего механизма взаимодействия субъектов образовательного процесса. В большинстве муниципальных и частных школ данная должность отсутствует в принципе, а функционал передаётся частично одному из заместителей директора по учебно-воспитательной работе, и частично возлагается на методиста (методистов). Однако реформирование системы общего образования на современном этапе, увеличение требованиям как к школе в целом, так и к отдельному педагогу в частности, доказывает необходимость существования данного руководителя второго уровня в школе.

\section{Материалы и методы исследования}

В процессе исследования использовались общелогические (анализ, индукция), теоретические (системный методы, обобщение) и эмпирические методы (наблюдение, описание, измерение).

\section{Результаты исследования}

Заместитель директора по научно-методической работе в современных условиях обязан быть профессиональным и компетентным в своей области менеджером, органичным носителем управленче- 
ской культуры. Г.М. Клочева выделяет три основных типа навыков управления в рамках развития управленческой культуры: технический (мастерство), межличностный (контактность, коммуникабельность) и концептуальный (способностью осмысливать и видеть организацию процесса как целостного явления) [2, с. 58].

По нашему мнению, чтобы стать настоящим руководителем в условиях современного социума, мало желания распоряжаться и эмоциональной напористости в отдаче приказов нижестоящим служащим. Необходимо быть высокообразованным, ответственным, корректным человеком, умеющим поставить себя на место подчинённого в данной конкретной ситуации, что в общеобразовательной организации наблюдается достаточно редко. В качестве причины некомпетентности руководства некоторых школ З.К. Багирова, например, называет переход первоклассных специалистов из системы образования в сферу бизнеса в связи с необходимостью «выживания» в условиях экономической нестабильности в стране [1, с. 42].

Современный руководитель школы - это, прежде всего, успешный с экономической точки зрения менеджер. Понятие менеджмента в отношении руководства общеобразовательной организации прочно входит в педагогическую науку. О.А. Любченко и С.И. Карпова вводят чисто экономическое понятие маркетинга как системы управленческой деятельности, определяющей поведение школы в рыночной среде, направленной на более эффективное удовлетворение образовательных потребностей путем изучения рынка образовательных услуг и рынка труда [3, с. 200]. Нам данная позиция представляется верной, так как современный потребитель вправе выбирать и требовать получения качественной услуги, особенно если это касается образования, ведь именно формальная квалификация определит в дальнейшем трудовую деятельность выпускника в обществе.

В быстро меняющихся условиях деятельности современной школе нужны молодые специалисты, чтобы путём грамотного методического сопровождения в рамках концепции непрерывного 
образования сформировать из них опытных педагогов, психологически и духовно привязанных к конкретному общеобразовательному учреждению и не стремящегося в поисках материальной выгоды к частой смене места работы. И здесь ключевая роль принадлежит именно заместителю директора по НМР, который обязан выявить и планомерно развивать таланты молодого педагога. Опираясь на труды Л.И. Пономаревой, исследующей процессы педагогического сопровождения и поддержки учащихся [4], считаем возможным перенести базовые элементы сопровождения и поддержки в методическую область по отношению к педагогам, и развиваем положение о системном методическом сопровождении педагогического состава общеобразовательной организации.

С самого начала преподавательской деятельности молодого педагога заместитель директора по НМР тестирует его способности и возможности с помощью различных видов мониторинга: посещение уроков и открытых мероприятий, исследование правильности ведения рабочей документации, отзывы наставника молодого педагога и руководителя предметной кафедры, в которую входит последний. В случае готовности молодого педагога к интеллектуальной и творческой активности, процесс методического сопровождения со стадии наблюдения переходит в активную фазу.

Во-первых, речь идёт о таком фундаменте педагогической деятельности, как профессиональное образование и его непрерывное совершенствование.

Во-вторых, заместитель директора по НМР помогает сформировать целостное представление о педагогической профессии во всех её тонкостях и о профессиональной миссии учителя, призванного воспитать всесторонне развитого гражданина нашей страны. Для этого необходимо научить начинающего педагога формулировать две базовые цели своей профессиональной деятельности: как построить максимально продуктивное обучение детей, и одновременно как способствовать своим каждодневным трудом стабильному повышению эффективности работы общеобразовательной организации. 
B-третьих, накануне начала нового учебного года заместитель директора по НМР должен скрупулёзно проверить соответствие составленных учителями рабочих программ по учебным предметам Положению о рабочей программе общеобразовательной организации.

Особое внимание следует уделить непрерывности трансляции педагогического опыта, для чего необходимо выявлять и стимулировать работу тех членов коллектива, у которых имеются способности к научно-педагогической деятельности. Настоящая трансляция опыта на должном уровне обеспечивается только участием педагогов с научными и научно-методическими статьями в конференциях различного уровня, проводимых на базе высших учебных заведений и научных организаций, с обязательной публикацией материалов в сборниках, выпущенных по итогам конференций.

Если заместитель директора по НМР является не просто руководителем, а профессиональным учёным, он может создать на базе своего общеобразовательного учреждения настоящую научную школу, участники которой не ограничатся публикациями уровня сборников тезисов и статей конференций, но будут пробовать себя в более сложных формах научного творчества: публикация в российских и зарубежных журналах, издание учебников, учебных и учебно-методических пособий, методических рекомендаций, сборников задач; написание коллективной или даже авторской монографии по итогам длительного периода педагогической деятельности. При этом заместитель директора по НМР с помощью непрерывного сотрудничества с вузами должен обеспечить научное рецензирование данных работ специалистами соответствующего уровня, которое поможет выявить достоинства и недостатки научно-педагогических изысканий работников школы, определить вектор дальнейшего продвижения к намеченной цели в рамках объекта и предмета исследования.

Одной из важнейших функций заместителя директора по НМР становится в современных условиях сопровождение и поддержка совместной работы учителей с обучающимися, выявление и развитие одарённых детей. Отдельного внимания заслуживает учебно-иссле- 
довательская работа обучающихся, преобразуемая с приобретением ими опыта научно-исследовательской работы.

И наконец, заместитель директора по НМР оказывает методическое сопровождение при аттестации педагогов на квалификационную категорию на протяжении всей аттестационной процедуры.

\section{Заключение}

Таким образом, в современной школе должность заместителя директора по научно-методической работе является необходимой и жизненно важной для обеспечения эффективной работы данной общеобразовательной организации. Будучи опытным менеджером, ответственным, коммуникабельным, способным к научной и методической работе на высоком уровне, такой руководитель обеспечивает, с одной стороны, стабильный профессиональный рост педагогического коллектива и формирование учебных компетенций обучающихся, с другой стороны, бесперебойное функционирование и непрерывное развитие самой школы, которая при высококвалифицированном заместителе директора по НМР имеет все шансы стать не просто местом обучения детей универсальным учебным действиям, но настоящим центром подготовки к получению высшего образования, осознанного профессионального самоопределения, полноценной социализации личности обучающегося в современном правовом государстве и гражданском обществе.

\section{Список литературы}

1. Багирова 3.К. Управленческая культура руководителя общеобразовательной школы: структура и содержание // Мир науки, культуры, образования. 2015. №2 (51). С. 40-42.

2. Клочева Г.М. Управленческая культура как детерминанта профессионализации педагога // Новый взгляд. Международный научный вестник. 2014. №4. С. 51-60.

3. Любченко О.А., Карпова С.И. Моделирование системы управления современной общеобразовательной школой с позиций системного подхода // Вестник Тамбовского университета. Серия: Гуманитарные науки. 2012. №7. С. 197-203. 
4. Пономарева Л.И. Соотношение парадигм сопровождения и поддержки в педагогической теории и практике // Педагогическое образование в России. 2014. №10. С. 171-174.

\section{References}

1. Bagirova Z.K. Upravlencheskaya kul'tura rukovoditelya obshcheobrazovatel'noj shkoly: struktura i soderzhanie [Management culture of the head of secondary school: structure and content]. Mir nauki, kul'tury, obrazovaniya, 2015, №2 (51), pp. 40-42.

2. Klocheva G.M. Upravlencheskaya kul'tura kak determinanta professionalizacii pedagoga [Management culture as a determinant of teacher professionalization]. Novyj vzglyad. Mezhdunarodnyj nauchnyj vestnik, 2014, №4, pp. 51-60.

3. Lyubchenko O.A., Karpova S.I. Modelirovanie sistemy upravleniya sovremennoj obshcheobrazovatel'noj shkoloj s pozicij sistemnogo podhoda [Modeling the management system of a modern secondary school from the standpoint of a systematic approach]. Vestnik Tambovskogo universiteta. Seriya: Gumanitarnye nauki, 2012, №7, pp. 197-203.

4. Ponomareva L.I. Sootnoshenie paradigm soprovozhdeniya i podderzhki v pedagogicheskoj teorii i praktike [Correlation of support and support paradigms in pedagogical theory and practice]. Pedagogicheskoe obrazovanie v Rossii, 2014, №10, pp. 171-174. 